\title{
Analisis Nilai Moral dan Nilai Sosial pada Kumpulan Cerpen Karya Ahmad Tohari sebagai Upaya Pemilihan Bahan Pembelajaran pada Siswa Kelas X SMAN 5 Pandeglang
}

\author{
Trisnawati ${ }^{1}$
}

${ }^{1}$ Universitas Mathla'ul Anwar Banten

\begin{tabular}{|c|c|}
\hline ARTICLE INFO & ABSTRACT \\
\hline $\begin{array}{l}\text { Article History: } \\
\text { Received 14.07.2018 } \\
\text { Received in revised } \\
\text { form 14.08.2018 } \\
\text { Accepted 19.08.2018 } \\
\text { Available online } \\
27.09 .2018\end{array}$ & $\begin{array}{l}\text { The study aims to determine the moral values and social values in a collection } \\
\text { of short stories by Ahmad Tohari as learning material in class X SMAN } 5 \\
\text { Pandeglang. The aim of this study to 1) Provide knowledge about the values } \\
\text { contained in short story, 2) Growing motivation in reading short story } \\
\text { literature, 3) Increasing interest in appreciating short stories, 4) Able to analyze } \\
\text { the values contained in short story literature, 5) Instill the positive values of } \\
\text { short stories in everyday life. The method used in this research is descriptive } \\
\text { analysis method. Descriptive method is the method used to make broader } \\
\text { conclusions. Research data collection techniques were carried out using } \\
\text { literature studies or documentation studies on Ahmad Tohari's short stories. } \\
\text { The steps in this descriptive study are, 1) Identify significant problems that can } \\
\text { be solved through the descritive method, 2) Formulate the problem clearly, 3) } \\
\text { Determine the purpose and benefits of research, 4) Conduct literature studies } \\
\text { related to problems, and 5) Collect and analyze data qualitatively. The steps of } \\
\text { data collection are reading Ahmad Tohari's short stories carefully, recording } \\
\text { the appropriate data, identifying and classifying data and making data } \\
\text { education. The results of the study indicate that the collection of short stories } \\
\text { by Ahmad Tohari contains many values, especially moral values and social } \\
\text { values. }\end{array}$ \\
\hline
\end{tabular}

DOI: $10.30653 / 006.201811 .9$

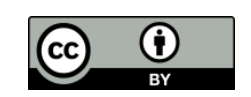

This is an open access article distributed under the terms of the Creative Commons Attribution 4.0 International License, which permits unrestricted use, distribution, and reproduction in any medium, provided the original work is properly cited. ๑ 2018 Trisnawati.

\section{PENDAHULUAN}

Pembelajaran dalam karya sastra merupakan pembelajaran yang mengandung banyak unsur-unsur kehidupan di dalamnya. Unsur-unsur kehidupan yang memberikan banyak motivasi serta cerminan pada pembacanya. Pembelajaran sastra pada peserta

${ }^{1}$ Corresponding author’s address: Universitas Mathla’ul Anwar Banten. Email: enatrisna1@gmail.com 
didik merupakan pembelajaran dalam mengapresiasi nilai-nilai kehidupan yang terkandung dalam cerpen. Peserta didik dituntut untuk mampu menganalisis nilai yang terkandung dalam cerpen sehingga siswa bisa mengambil banyak manfaat dalam karya cerpen untuk diterapkan dalam kehidupan sehari-hari. Pengajaran sastra memiliki peran bagi pemupukan kecerdasan siswa dalam semua aspek, termasuk nilai moral dan nilai sosial. Melalui apresiasi sastra, misalnya kecerdasan intelektual, emosional, dan spiritual siswa dapat dilatih serta dikembangkan. Siswa tidak hanya terlatih untuk membaca saja, tetapi harus mampu mencari makna dan nilai-nilai dalam sebuah karya sastra (Noor, 2011: 46).

Nilai moral yang terkandung dalam cerpen merupakan nilai yang berkaitan dengan sikap tokoh dalam cerpen. Menurut KBBI moral merupakan ajaran tentang baik buruk perbuatan dan kelakuan mengenai akhlak, budi pekerti, kewajiban. Sedangkan moral menurut Darajat (Komaruddin, 1985: 9) adalah kelakuan yang sesuai ukuran atau nilainilai masyarakat yang timbul dari hati dan bukan paksaan dari luar, yang disertai pula oleh rasa tanggung jawab atas tindakan tersebut. Moral merupakan akhlak baik atau buruk manusia dalam melakukan tindakan atau perbuatan, dalam analisis cerpen karya Ahmad Tohari ini, siswa dituntut mampu untuk menganalisis nilai moral yang terkandung dalam cerpen. Selain nilai moral yang terkandung penelitian ini bertujuan untuk menganalisis nilai sosial dalam cerpen karya Ahmad Tohari.

Nilai sosial merupakan nilai yang berkaitan dengan masyarakat dan memiliki tujuan untuk menyelesaikan masalah yang dibahas dengan jalan keluar sebanyak mungkin dan tidak merugikan orang lain. Nilai sosial merupakan nilai yang dilakukan dengan cara bermusyawarah dengan masyarakat atau sekelompok orang untuk menyelesaikan suatu masalah dan mencari solusi dalam permasalahan tersebut. Menurut Soerjono Soekonto ( Waluya, 2007) mengemukakan bahwa nilai sosial sebagai konsepsi abstrak dalam diri manusia mengenai apa yang dianggap baik dan apa yang dianggap buruk. Sedangkan menurut Amir (Sukatman, 1992: 26) merupakan nilai yang mendasari, menuntun dan menjadi tujuan tindakan dan hidup sosial manusia dalam melangsungkan, mempertahankan dan mengembangkan hidup sosial manusia. Berbeda dengan yang dikemukakan oleh Goeman (Sukatman, 1992: 27) menilai sosial merupakan kaidah yang melandasi manusia untuk menyesuaikan diri terhadap lingkungan geografis, sesama manusia, dan kebudayaan alam sekitar. Untuk melihat nilai sosial dalam karya sastra kita dapat menganalisis dalam nilai yang berupa tradisi, konvensi dan norma masyarakat yang ada dalam sastra. Seperti yang dikatakan oleh Wellek \& Warren (1989: 109) bahwa sastra sebagai institusi sosial yang memakai medium bahasa, dalam menyampaikan pesan disalurkan dalam bentuk simbolisme yang berupa konvensi dan norma sosial. Biasanya simbolisme itu berkaitan dengan situasi sosial tertentu, seperti politik, ekonomi, dan sebagainya.

Dalam novel laskar pelangi karya Andrea Hirata (2007) banyak memuat nilai-nilai sosial seperti, tolong-menolong, kebersatuan hidup, saling menghargai antar sesama, toleransi, silaturahmi dan sebagainya. Jadi dalam sebuah karya sastra nilai sosial merupakan nilai yang penting yang dapat diterapkan oleh peserta didik dalam kehidupan sehari-hari dalam bergaul dengan sesama dan dengan masyarakat di lingkungan sekitar, sehingga penelitian ini dapat memberikan arahan serta nilai yang positif bagi peserta didik dalam bergaul dengan masyarakat. Dalam bersosialisasi peserta didik harus mengetahui cara bergaul yang baik, memiliki kesopanan antar sesama maupun kepada orang yang lebih tua, senantiasa bekerja sama dan membantu sesama, dan sebagainya. 
Dalam menganalisis sebuah karya sastra kendala yang dihadapi oleh peserta didik yaitu kurangnya sumber atau buku yang berkaitan dengan analisis cerpen. Guru harus senantiasa kreatif dan berusaha memberikan sumber kepada peserta didik apabila di sekolah sumber buku terbatas, sehingga dengan sumber yang banyak siswa akan lebih termotivasi dalam melakukan analisis sebuah karya sastra cerpen. Kendala-kendala yang dihadapi oleh peserta didik akan mengurangi semangat belajar para peserta didik, oleh sebab itu pihak sekolah maupun guru bahasa dan sastra Indonesia di tuntut untuk kreatif dalam pembelajaran sastra maupun berusaha mencari sumber-sumber buku yang dibutuhkan oleh peserta didik.

Nilai moral dan nilai sosial dalam penelitian ini menjadi kajian dalam analisis cerpen karya Ahmad Tohari. Nilai moral merupakan ajaran yang berfungsi sebagai pedoman untuk mengatur kehidupan masyarakat. Dalam karya sastra, moral merupakan ajaran kesusilaan yang bertujuan mengajarkan sesuatu secara langsung atau tidak langsung kepada pembaca. Nurgiyantoro (2010: 320-321) mengemukakan bahwa secara umum moral mengarah pada pengertian atau ajaran tentang baik buruk yang diterima umum mengenai perbuatan, sikap, kewajiban, akhlak, budi pekerti, dan susila. Istilah "bermoral", misalnya tokoh bermoral tinggi, berarti mempunyai pertimbangan baik dan buruk. Berbeda dengan Nurgiyantoro wujud ajaran moral menurut Zuriah (2007: 27-32) dikelompokkan dalam tiga ruang lingkup yaitu akhlak terhadap Tuhan yang Maha Esa, akhlak terhadap sesama manusia, dan akhlak terhadap lingkungan alam dan sosial masyarakat.

Dalam penelitian ini analisis nilai moral menggunakan tiga ruang lingkup menurut Zuriah. Setelah melakukan penelitian berdasarkan nilai moral peneliti melanjutkan penelitian berdasarkan nilai sosial. Nilai sosial merupakan nilai yang terkandung dalam cerpen yang sifatnya berkenaan pada perilaku manusia pada saat bergaul dengan sesama di lingkungan masyarakat sekitar. Menurut Amir (Sukatman, 1992: 26) mengemukakan bahwa nilai sosial merupakan nilai yang mendasari, menuntun, dan menjadi tujuan tindakan dan hidup sosial manusia dalam melangsungkan, mempertahankan dan mengembangkan hidup sosial manusia. Dalam karya sastra sering terdapat nilai-nilai sosial yang disebut aspek sosiologis sastra. Termuatnya nilai sosial dalam sastra merupakan akibat logis dari kenyataan bahwa sastra ditulis oleh sastrawan yang hidup di tengah masyarakat dan sangat peka dengan masalah sosial. Sastrawan individu tetapi bisa mewakili masyarakatnya. Nilai sosial diharapkan menjadi sebuah alat solidaritas dikalangan anggota kelompok masyarakat. Nilai sosial juga berfungsi untuk mengontrol perilaku manusia dengan daya tekan dan daya mengikat tertentu agar orang berperilaku sesuai dengan nilai yang dianutnya. Menurut Nottingham (1994: 45) mengemukakan bahwa nilai sosial seringkali menjadi pegangan hidup oleh masyarakat luas dalam menentukan sikap di kehidupan sehari-hari, juga menjadi nilai hidup manusia dalam berinteraksi dengan manusia lainnya.

Menurut Zubaedi (2006: 13) mengemukakan nilai-nilai sosial secara umum yang akan di analisis yaitu nilai pengabdian, tolong menolong, kekeluargaan, kesetiaan, kepedulian, tanggung jawab, disiplin, empati, keserasian hidup, keadilan, toleransi, kerjasama, dan demokrasi. Nilai-nilai tersebut akan dianalisis berdasarkan cerpen karya Ahmad Tohari, sehingga akan ditemukan nilai-nilai yang terkandung dalam cerpen.

Setelah menganalisis nilai moral dan nilai sosial dalam cerpen karya Ahmad Tohari, hasil analisis cerpen akan digunakan sebagai alternatif atau dimanfaatkan sebagai bahan ajar sastra. Bahan ajar menurut Prastowo (2011: 16) mengemukakan bahwa bahan ajar 
adalah segala bentuk bahan yang digunakan untuk membantu guru atau instruktur dalam melaksanakan proses pembelajaran di kelas. Bahan yang dimaksud dapat berbentuk bahan tertulis maupun bahan tidak tertulis. Pendapat lainnya menyebutkan bahwa bahan ajar adalah seperangkat materi yang disusun secara sistematis, baik tertulis maupun tidak tertulis sehingga tercipta lingkungan atau suasana yang memungkinkan peserta didik untuk belajar. Pendapat lainnya juga mengatakan bahwa bahan ajar adalah informasi, alat, dan teks yang diperlukan guru atau instruktur untuk perencanaan dan penelaahan implementasi pembelajaran.

\section{METODE}

Analisis nilai moral dan nilai sosial dalam cerpen keagamaan menggunakan metode deskriptif analisis. Metode deskriptif adalah metode yang mendeskripsikan fakta-fakta yang kemudian disusul dengan analisis. Mula-mula data dideskripsikan dengan maksud untuk menemukan nilai-nilai yang dianalisis yaitu nilai moral dan nilai sosial, bahkan juga diperbandingkan. Metode deskriptif juga merupakan data yang diperoleh apa adanya. Tujuannya adalah mendeskripsikan data atau memberikan gambaran secara sistematis (Semi, 1993: 24).

Teknik pengumpulan data dalam penelitian ini menggunakan studi kepustakaan dan studi dokumentasi terhadap cerita pendek karya Ahmad Tohari. Aplikasi studi dokumentasi dilakukan oleh peneliti membaca cerpen karya Ahmad Tohari secara cermat dan mendalam untuk memahami isinya, dan memahami unsur-unsur yang membangun cerpen tersebut, serta memahami unsur-unsur yang berkaitan dengan nilai-nilai moral yang terkandung dan nilai-nilai sosial dalam cerpen.

Dalam penelitian ini dokumen atau data diperoleh dari keempat cerpen karya Ahmad Tohari yang merupakan cerpen yang memiliki nilai-nilai yang baik dalam kehidupan sehari-hari. Nilai yang menjadi bahan analisis dalam penelitian ini yaitu nilai moral dan nilai sosial. Kumpulan cerpen karya Ahmad Tohari yang akan dianalisis yaitui 1) Daruan, 2) Sayur Bleketupuk, 3) Harta Gantungan dan 4) Bulan Kuning Sudah Tenggelam.

Teknik analisis data bertujuan untuk mengungkapkan nilai moral dan nilai sosial yang terjadi dalam cerita pendek karya Ahmad Tohari. Analisis data yang digunakan dalam penelitian adalah analisis deskriptif kualitatif. Analisis deskriptif kualitatif adalah proses mencari serta menyusun secara sistematis data yang diperoleh dari hasil pengumpulan data di lapangan, kemudian diklasifikasi berdasarkan pokok kajian dan dimaknai berdasarkan referensi yang menjadi rujukan.

\section{PEMBAHASAN}

Dalam hasil penelitian, penulis mendapatkan nilai moral dan nilai sosial dalam setiap cerita yang di analisis. Nilai moral merupakan nilai tokoh dalam cerita yang di ungkapkan melalui adegan-adegan yang dilakukan oleh para tokoh, sedangkan nilai sosial yang dianalisis, penulis mendapatkan hasil penelitian dari alur cerita yaitu tokoh dengan tokoh lain yang melakukan beberapa adegan atau cerita berkaitan dengan lingkungan masyarakat maupun lingkungan alam. 


\section{Cerpen berjudul Daruan}

Adapun data yang diperoleh dari analisis data yang dilakukan, yaitu.

\section{Nilai Moral}

\section{Akhlak Kepada Tuhan yang Maha Esa}

Kutipan: "Dalam sembahyangnya, tiba-tiba Daruan merasa beruntung mendapat peluang berdoa. Anehnya dia tergagap dan gagal menemukan doa yang pantas dikemukakan kepada Tuhan."

Akhlak yang ditunjukkan Daruan kepada Tuhan yang Maha Esa yaitu ia melakukan sembahyang dan berdoa.

Sikap terhadap Sesama

Kutipan: "Kebetulan aku punya uang sedikit. Pakailah untuk ongkos pulang dan sisanya buat jajan anak."

Sikap terhadap sesama manusia ditunjukkan oleh Muji dalam menolong Daruan yang membutuhkan uang.

\section{Nilai Sosial}

\section{Keserasian Hidup}

Kutipan: "Sebuah paket pos diterima Daruan dari muji di Jakarta. Kiriman dalam kertas payung itu mengakhiri masa perhentian selama dua tahun yang hampir menghabiskan kesabaran Daruan. Isi paket pos itu sungguh menggembirakan Daruan. Hati Daruan melambung ketika melihat namaya tercetak jelas pada kulit buku yang berhias gambar gadis cantik dengan rambut tergerai itu".

Dalam kutipan menjelaskan bahwa keserasian hidup Daruan muncul karena apa yang diharapkan olehnya tercapai sehingga hidup seakan berpihak kepadanya.

\section{Kerjasama}

Kutipan: "Dalam surat pengantar yang diselipkan dalam paket pos itu, Muji berkata bahwa dia sendirilah yang bertindak menjadi penerbit novel Daruan. Selanjutnya Muji bilang bahwa resiko yang dipikulnya tidak ringan, karena dia belum berpengalaman dan terutama karena tidak mempunyai jaringan pemasaran".

Dalam kutipan kerjasama yang terjalin antara kedua sahabat yaitu Daruan dan Muji, Muji senantiasa membantu Daruan untuk menerbitkan novelnya dengan segala resiko yang dipikulnya.

Kekeluargaan

Kutipan: "Sudah sekian lama Daruan tersiksa oleh ketidakmampuan memberi nafkah kepada istri dan anaknya. Daruan sekian lama hidup menjadi tanggungan istrinya yang membuka warung di depan rumah."

Nilai kekeluargaan yang terjalin sepasang suami istri yang senantiasa saling membantu satu sama lain pada saat Daruan sebagai suami tidak bisa mencari nafkah dan istrinya senantiasa mencukupi kebutuhan Daruan. 
Kepedulian

Kutipan: "Penerbit beneran biasa memberi uang muka kepada penulis. Sedangkan aku, kamu tahu, sebenarnya tak bisa disebut penerbit. Maka aku hanya bisa berjanji membagi dua sama banyak hasil penjualan buku itu menjadi hakmu sepenuhnya. Itu janjiku."

Kepedulian ditunjukkan oleh Muji kepada Daruan bahwa ia akan memberikan keuntungan hasil penjualan buku menjadi hak sepenuhnya Daruan.

Empati

Kutipan: "Kebetulan aku punya uang sedikit. Pakailah untuk ongkos pulang dan sisanya buat jajan anak."

Rasa empati Muji kepada sahabatnya Daruan sangatlah mencerminkan sikap yang baik terhadap sahabatnya, ia rela memberikan uang kepada Daruan untuk ongkos atau jajan anaknya.

\section{Cerpen berjudul Sayur Bleketupuk}

\section{Nilai Moral}

Akhlak Taat Kepada Perintah Tuhan yang Maha Esa

Kutipan: "Parsih amat gelisah. Ibadah magrib membuat Parsih merasa agak tenang."

Kutipan di atas menunjukkan bahwa tokoh Parsih yang senantiasa lebih tenang dalam menghadapi masalah ketika ia melakukan ibadah kepada Tuhan YME.

Sikap Kepada Sesama

Kutipan: "Hampir jam tujuh malam dalbun pulang sambil membawa kutukan kepada $m$ andor yang datang sangat terlambat. Wajahnya tegang karena merasa telah membiarkan istri dan kedua anaknya terlalu lama menunggu."

Kutipan terhadap sikap marah tokoh kepada sang mandor yang ditunjukkan dalam kutipan.

\section{Sikap Rasa Kasih Sayang}

Kutipan:"Masih berdiri didekat dipan anak-anaknya, Parsih mendengar keluhan Dalbun kepada mandor. Ada yang terasa tiba-tiba jatuh membebani dadanya. Air matanya menitik lagi. Dan terlihat dari balik genangan air mata, wajah Darto dan Darti menjadi begitu bercahaya."

Sikap tokoh Parsih yang begitu menyayangi anak-anaknya sehingga ia senantiasa menitikkan airmata atas penyesalannya.

\section{Nilai Sosial}

Kekeluargaan

Kutipan: "Selesai makan anak kedua anak itu lari keluar. Mereka biasa numpang nonton televisi di rumah Pa RT sebelum magrib. Parsih ingin menahan kedua anaknya tapi sudah terlambat. Darti dan Darto sudah masuk ke rumah Pa RT."

Kekeluargaan yang terjalin antara anak Parsi yakni Darti dan Darto yang terlihat dalam kutipan yaitu kebiasaan Darti dan Darto yang selalu menonton televisi di rumah Pa RT. 


\section{Kesetiaan}

Kutipan: "Sebelum terlihat oleh istrinya, Dalbun sudah mengeluarkan uang gajinya dari saku. Akan segera diberikan semua kepada Parsih."

Kesetiaan yang ditunjukkan tokoh Dalbun yaitu segera memberikan uang hasil jerit payahnya kepada istrinya Parsih supaya istrinya tidak kecewa atas kedatangannya yang terlambat.

Kepedulian

Kutipan: "Aku tidak sampai hati memaksa mereka bangun, "jawab Parsih dan air matanya mulai berjatuhan. Dalbun menunduk dan melepaskan napas panjang. Dia pun merasa tidak tega membangunkan kedua anaknya yang begitu lelap tidur."

Kepedulian yang ditunjukkan Parsih terhadap anak-anaknya yaitu ketika ia tidak tega untuk membangunkan anaknya ketika terlelap tidur.

\section{Cerpen berjudul Harta Gantungan}

\section{Nilai Moral}

Sikap kepada Tuhan yang Maha Esa dengan menunaikan ibadah menurut ajaran Tuhan YME

Kutipan: "Setelah matahari terbenam, surau itu gelap dan merana. Burung hantu yang sedang mengintai ikan yang suka bertengger di atapnya. Hanya beberapa orang yang biasa salat di sana. Di antaranya dua orang penyadap nira. Sering juga ada pedagang keliling singgah untuk menunaikan ibadah. Selebihnya hanya kadang-kadang adalah saya dan kang Nurya."

Sikap taat kepda perintah Tuhan YME ditunjukkan oleh toko saya yaitu Markotob dan kang Nurya yang senantiasa beribadah di surau itu.

Sikap Tegas

Kutipan: "Aku sudah bilang, umurku sudah melewati usia kanjeng nabi. Dan bila aku harus mati karena bengkak di leher ini, ya tidak apa-apa. Yang penting aku masih punya harta gantungan."

Tokoh kang Nurya bersikap tegas bahwa kerbau yang diurusnya tidak akan ia jual untuk mengobati penyakitnya, kerbaunya dijual hanya untuk biaya mengurus jenazahnya apabila kelak ia meninggal.

\section{Nilai Sosial}

Kesetiaan

Kutipan: "Maka kang Nurya, yang mengaku sudah berusia lebih tua daripada umurnya kanjeng Nabi, hanya bisa mengakrabi seekor kerbaunya. Hari-hari kang Nurya adalah hari-hari bersama binatang itu. Karena keakraban itu, bau kerbau adalah bau kang nurya juga. Jadilah, di kampung kami lelaki tua itu dipanggil dengan sebutan lucu Nurya kebo."

Kesetiaan yang ditunjukkan oleh kang Nurya terhadap hewan peliharaannya sangatlah terlihat dari ia yang senantiasa menghabiskan hari-harinya bersama kerbau peliharaannya.

Kekeluargaan

Kutipan: "Bahkan terasa sangat jujur, karena menurut kang Nurya, kerbau adalah segalanya. Kerbau sudah menjadi sahabat dan bagian terpenting dalam hidupnya." 
Kekeluargaan yang diperlihatkan dari tokoh kang Nurya terlihat bahwa ia sudah menganggap bahwa kerbau segalanya dalam hidup seperti keluarga yang begitu berarti baginya.

\section{Tanggung Jawab}

Kutipan: "Saya perhatikan kang Nurya menuruni anak tangga untuk mencapai titian. Tangan kirinya lekat pada bambu pegangan. Langkahnya mantap karena dia sudah sangat terbiasa dengan titian itu. Di kejauhan saya melihat kang Nurya masih sempat menjambret daun-daun singkong liar yang tumbuh di tepi selokan. Pasti demi kerbaunya."

Rasa tanggung jawab ditunjukkan oleh tokoh kang Nurya yang senantiasa bertanggung jawab atas kerbaunya, kang Nurya yang sakit selalu berusaha untuk mencari makanan untuk kerbaunya.

Tolong Menolong

Kutipan: "Untung ada tetangga yang setia menunggu kang Nurya dan memberinya makan dan minum. Kang Nurya sudah terlihat parah, tetapi tetangga yang menunggu hanya bisa kebingungan karena tidak tahu apa yang harus dilakukan selain memberi air bila kang Nurya minta minum."

Tolong menolong ditunjukkan oleh para tetangga kang Nurya pada saat kang Nurya sakit, mereka saling bergantian menunggu kang Nurya apabila kang Nurya ingin makan dan minum.

Empati

Kutipan: "Kami melihat anak kang Nurya meneteskan air mata. Tetapi saya sendiri merasa jembar hati. Ya, rupanya jauh disana, ada calon pengantin yag dapat keberuntungan pada saatsaat terakhir. Karena kakeknya rela mati kena tumor demi mempertahankan harta gantungan. Calon pengantin itu pun mendapat biaya untuk menikah. Semoga diberkati."

Rasa empati di tunjukkan oleh tokoh Markotob yang mana Markotob ber empati dibalik kematian kang Nurya cucunya mendapat keberkahan bisa dinikahkan dengan memakai biaya penjualan kerbau kang Nurya yang sangat dipertahankannya, walaupun itu bukan yang diamanatkan oleh kang Nurya.

\section{Cerpen berjudul Bulan Kuning Sudah Tenggelam}

\section{Nilai Moral}

Sikap Kasih Sayang terhadap Sesama

Kutipan: "Apabila aku bukan Yuning, barangkali aku bisa menemukan cara yang lebih santun untuk menjembatani beda pendapat antara diriku dan ayah. Oh, engkaulah laki-laki, meskipun bukan ayah kandung tetapi telah membesarkan diriku dalam haribaan kasih sayang."

Sikap kasih sayang yang ditunjukkan oleh ayah Yuning yang senantiasa membesarkan Yuning dengan penuh kasih sayang walaupun bukan ayah kandungnya.

\section{Sikap Teguh pada Pendirian}

Kutipan: "Ah, Yuning, kemarilah. Sudah malam. Apalah perlunya memperpanjang maslaah yang sudah jelas. Soal permintaan orangtuamu itu, aku sudah memutuskan menolaknya karena aku lebih suka bernaung di bawah atap buatanku sendiri." 
Sikap teguh pada pendirian ditunjukkan oleh tokoh Engkos suami Yuning, bahwa ia lebih suka tinggal di atap buatannya sendiri dibandingkan tinggal di atap ayah Yuning walaupun atap itu yang kokoh dan bagus.

Sikap Gelisah

Kutipan: "Ketika bulan kuning sempurna tenggelam, telingaku berdering. Aku merasa duduk di atas udara. Sekelilingku lengang dan begitu mencekam. Aku terperanjat ketika mengetahui orang yang diagungkan itu adalah ayahku sendiri. Aku tergagap dan tercekik. Hampir aku berteriak keras apabila tidak kudengar suara suamiku. Dan ternyata itu mimpi buruk."

Rasa gelisah ditunjukkan oleh tokoh Yuning yang merasa bersalah karena sudah berbeda pendapat dengan ayahnya sampai ayahnya jatuh sakit, terjadilah mimpi buruk yang memberikan gambaran bahwa ayahnya akan segera meninggal.

Akhlak kepada Tuhan yang Maha Esa dengan Melakukan Sembahyang

Kutipan: "Katanya, kemudian ayah mengajak ibu masuk ke kamar. Untuk sembahyang." Kita wajib mohon ampun kepada Tuhan, sumber segala keteduhan rasa dan kebahagiaan," kata ayah."

Akhlak taat beribadah kepada Tuhan YME ditunjukkan oleh ayah pada kutipan diatas, ayah senantiasa sembahyang dan berdoa untuk memohon ampun dan berdoa agar hatinya tenang dalam menghadapi berbagai masalah.

\section{Nilai Sosial}

\section{Kesetiaan}

Kutipan: "Tetapi aku senang tinggal disana, karena Koswara setiap hari berada di tempat itu. Ini jawaban yang amat bersahaja, namun bagiku tak bisa ditawar-tawar. Koswara yang kukenal sejak masih dikampus adalah segala-galanya bagiku, dan ini jangan dianggap berlebih-lebihan. Itulah kira-kira yang kusampaikan kepada ayah pada malam itu."

Sikap kesetiaan yang di tunjukkan oleh tokoh Yuning yakni ia tetap akan tinggal dengan Koswara apapun keadaannya, karena Koswara merupakan orang yang begitu berarti dalam hidupnya.

\section{Kepedulian}

Kutipan: "Untuk itu, ayah telah menyiapkan segala sesuatunya buat kalian berdua. Selain rumah, ayah telah membuka tiga hektar kebun cengkeh. Bila suaminya hendak mengusahakan kolam ikan, tanah yang tersedia cukup luas."

Kepedulian yang ditunjukkan oleh ayah Yuning benar-benar tulus ia rela memberikan tanah dan rumahnya untuk Yuning dan Koswara sehingga Yuning tidak susah dalam memperoleh kebahagiaan dalam rumah tangganya.

\section{Kerjasama}

Kutipan: "Baiklah, anakku. Baiklah. Sekarang daripada cakap ini menjadi berkepanjangan maka dengarlah. Ayah dan ibu meminta kau tinggal dekat dengan kami dengan alasan yang sederhana. Kami sudah tua dan kaulah satu-satunya yang telah kami besarkan. Ini wajar dan sama sekali bukan tagihan balas budi."

Ayah Yuning meminta kerjasama kepada anaknya agar mau tinggal bersama dengan ayah dan ibunya, karena keadaan mereka sudah tua tidak akan ada yang mau mengurus mereka selain Yuning. 


\section{Tolong Menolong}

Kutipan: "Pada rakaat pertama, ayah bersujud dan terus bersujud. Beliau tidak pernah bangun kembali. Karena merasakan ada kejanggalan, ibu membangunkan ayah. Tetapi beliau roboh dan sudah tak sadarkan diri. Dengan pertolongan para tetangga, ayah dilarikan ke rumah sakit."

Sikap tolong menolong ditunjukkan oleh para tetangga yang senantiasa menolong tokoh ayah yang tidak sadarkan diri.

Tanggung Jawab

Kutipan: "Ah, Yuning. Suatu saat menjelang remaja kau jatuh sakit. Parah, sehingga kau harus dirawat di rumah sakit di Bandung. Ingatlah baik-baik, siapa yang paling setia menjengukmu, membiayai perawatanmu hingga kau sembuh?".

Sikap tanggung jawab yang ditunjukkan oleh orangtua Yuning yang senantiasa mengurus segala apapun urusan dalam hidup Yuning.

Empati

Kutipan:"Entah berapa lama aku tetap bergeming menatap foto ayah. Yang kurasakan kemudian adalah sentuhan lembut tangan ibu mengelus pundakku. "Mari geulis, anakku. Jangan perturutkan hati yang sedang murka."

Rasa empati ditunjukkan ibu untuk anaknya Yuning atas segala kesedihan dan keresahan hatinya.

Pengabdian

Kutipan: "Tetaplah dalam kelemahlembutan tri sejati, itulah caranya. Apabila dengan cara itu kau masih dihinakan, tiba saat bagimu untuk berbuat membela martabatmu sendiri sebagai manusia. Tetapi sepanjang pengalamanku, Yuning, bagaimanapun gagah seorang laki-laki dia akan merunduk dihadapan citra seorang perempuan sejati. Boleh jadi kata-kataku berlebihan, namun cobalah uji kebenarannya."

Pengabdian yang ditunjukkan oleh ibu Yuning memberikan gambaran kepada Yuning bahwa pengabdian kepada seorang suami haruslah dijunjung.

Dari hasil penelitian di atas nilai moral dan nilai sosial yang didapatkan oleh penulis bisa memberikan gambaran atau cerminan manusia dengan sesama manusia lainnya agar berperilaku sesuai dengan nilai dan norma yang ada dalam kehidupan sehari-harinya. Senantiasa menjaga keutuhan dalam menjalin komunikasi antar sesama dan masyarakat, sehingga terjalin komunikasi yang dapat memberikan manfaat bagi kehidupan di sekitar. Dalam penelitian ke 4 cerpen nilai moral yang didapatkan yaitu nilai moral terhadap akhlak kepada Tuhan yang Maha Esa dan kepada sesama manusia, memiliki sikap dan rasa kasih sayang antar sesama, serta nilai sosial yang didapatkan memberikan gambaran dalam berperilaku seperti kepedulian terhadap sesama, kesetiaan dalam cinta kasih terhadap sesama, rasa empati, rasa tanggung jawab dalam tugas dan kewajiban, terjalinnya kerjasama yang baik antar sesama dan sebagainya.

\section{SIMPULAN}

Dalam cerpen 1 sampai 4 memiliki nilai moral dan nilai sosial, nilai moral yang terkandung dalam cerpen merupakan nilai-nilai yang bisa dijadikan pedoman dalam kehidupan sehari-hari. Cerpen karya Ahmad Tohari merupakan cerpen yang banyak 
memiliki amanat serta memiliki nilai-nilai yang akan menjadikan hidup lebih bermanfaat, khususnya nilai moral akan menjadikan seseorang bisa membedakan baik buruknya sikap ataupun perbuatan yang dilakukan, serta nilai sosial akan menjadikan seseorang bisa berkomunikasi dengan lingkungan sekitar dan masyarakat, sehingga akan terjalin silaturahmi yang baik.

Penulis menemukan nilai moral dalam cerpen 1 yang berjudul Daruan yaitu akhlak kepada Tuhan yang Maha Esa, sikap terhadap sesama, dan nilai sosial dalam cerpen 1 yaitu keserasian hidup, kerjasama, kekeluargaan, kepedulian, dan empati. Cerpen 2 yang berjudul Sayur Bleketupuk penulis menemukan nilai moral yaitu akhlak terhadap Tuhan yang Maha Esa yaitu taat kepada perintah Tuhan, sikap terhadap sesama, dan sikap rasa kasih sayang dan nilai sosial dalam cerpen yaitu kekeluargaan, kesetiaan, dan kepedulian. Cerpen 3 yang berjudul Harta Gantungan penulis menemukan nilai moral yaitu menjalankan perintah Tuhan dengan cara beribadah menurut ajaran Tuhan yang Maha Esa dan sikap tegas, dan nilai sosial dalam cerpen 3 yaitu kesetiaan, kekeluargaan, tanggung jawab, tolong menolong dan empati. Nilai moral yang terdapat dalam cerpen 4 yang berjudul Bulan Kuning Sudah Tenggelam yaitu sikap kasih sayang terhadap sesama, sikap teguh pada pendirian, sikap gelisah, dan akhlak kepada Tuhan yang Maha Esa dengan sembahyang, dan nilai sosial dalam cerpen 4 yaitu kesetiaan, kepedulian, kerjasama, tolong menolong, tanggung jawab, empati, dan pengabdian. Nilai moral maupun nilai sosial selain dijadikan pedoman hidup, nilai moral dan nilai sosial cerpen bisa dijadikan bahan ajar dan bermanfaat bagi siswa dalam mempelajari karya sastra khususnya dalam karya sastra cerpen.

\section{REFERENSI}

Andi, P. (2011). Panduan kreatif membuat bahan ajar inovatif. Yogyakarta: Diva Press.

Bagja, W. (2007). Sosiologi: Menyelami fenomena sosial di masyarakat. Jakarta: Setia Purna.

Elizabeth, K. N. (1994). Agama dan masyarakat. Jakarta: Raja Grafindo Persada.

Komarudin. (1985). Kamus istilah skripsi dan tesis. Bandung: Angkasa.

Noor, R. (2011). Pendidikan karakter berbasis sastra; Solusi pendidikan moral yang efektif. Yogyakarta: Ar-Ruzz Media.

Nurgiyantoro, B. (2010). Teori pengkajian fiksi. Yogyakarta: Gadjah Mada University Press.

Semi, A. (1993). Rancangan pengajaran bahasa dan sastra Indonesia. Bandung: Angkasa.

Sukatman. (1992). Nilai-nilai kultural edukatif dalam peribahasa Indonesia. Tesis (Tidak dipublikasikan). Malang: IKIP Program Pasca Sarjana.

Sugiyono.(2013). Metode penelitian pendidikan (Pendekatan kuantitatif, kualitatif, dan RED). Bandung: Alfabeta.

Tarigan, H.G. (1984). Prinsip-prinsip dasar sastra. Bandung: Angkasa. 
Jurnal Artikula 2018, 1(1),17-28

Wellek, R., \& Warren, A. (1989). Teori kesusasteraan. Jakarta: Gramedia.

Zuriah, N. (2005). Metodologi penelitian sosial dan pendidikan. Jakarta: Bumi Aksara. 